\title{
ANTEPROJETO DE REFORMA E AMPLIAÇÃO DO TERMINAL RODOVIÁRIO ADILMAR DE PAIVA GADELHA NA CIDADE DE SOUSA/PB
}

\author{
PRELIMINARY DRAFT REFORM AND ENLARGEMENT OF THE \\ ADILMAR ROAD TERMINAL OF PAIVA GADELHA IN THE CITY OF \\ SOUSA / PB
}

\author{
Diógenes Casimiro De Oliveira ${ }^{1}$ \\ Melina Cavalcanti de Melo Bichinho ${ }^{2}$ \\ Ezio Luiz Martins Simões ${ }^{3}$ \\ Camilla Furtado de Figueiredo ${ }^{4}$ \\ André Ferreira Costa ${ }^{5}$ \\ Marjorie Maria Abreu Gomes de Farias ${ }^{6}$
}

\footnotetext{
${ }^{1}$ Graduando em Arquitetura e Urbanismo pela Faculdade Santa Maria.

${ }^{2}$ Possui graduação em Arquitetura e Urbanismo pela Universidade Federal da Paraíba (UFPB 2016), especialização em Gestão de Políticas do Patrimônio Cultural pela Faculdade Maurício de Nassau (2018) e mestrado em Desenvolvimento Urbano (MDU) pelo Departamento de Arquitetura e Urbanismo da Universidade Federal de Pernambuco (UFPE - 2019), canalizando seus estudos para o projeto paisagístico e o bem-estar. Exerce o cargo de arquiteto como técnica na Prefeitura Municipal de Marí/ PB desde 2016, atuando na elaboração de projetos arquitetônicos e urbanos. É docente na Faculdade Santa Maria (FSM) desde 2018.

${ }^{3}$ Possui graduação em Arquitetura e Urbanismo pelo Centro Universitário de João Pessoa (2012) e mestrado pela Universidade Federal da Paraíba (PPGAU-UFPB). Atualmente é professor nas Faculdades Integradas de Patos-PB (FIP), mas também já trabalhou como professor na Faculdade Santa Maria de Cajazeiras-PB (FSM). Atua principalmente nos seguintes temas: requalificação urbana, bioclimatismo, projeto participativo e arquitetura. Além das atividades profissionais, é acadêmico do curso de Engenharia Civil pela UFCG - CCTA - campus Pombal-PB.

${ }^{4}$ Graduada em Arquitetura e Urbanismo pela Universidade Federal da Paraíba (2014), pós-graduada Habitação Social e Direito à Cidade pela Universidade Federal da Bahia (2016), pós-graduada em Arquitetura, Gestão e Construção de Edificações Sustentáveis pela Faculdade Unyleya (2016), mestre em Engenharia de Energias Renováveis com dissertação voltada para a pesquisa de alternativas de materiais de construção sustentáveis pela Universidade Federal da Paraíba (2017). Atualmente, é docente da Faculdade Santa Maria (FSM) e no Centro Universitário de João Pessoa (UNIPE), ambos no curso de Arquitetura e Urbanismo.

${ }^{5}$ Desde 2016 é professor da Faculdade Santa Maria de Cajazeiras, atuando no curso de Arquitetura e Urbanismo e no curso de Engenharia Civil. Possui graduação em Engenharia Civil pela Universidade Federal da Paraíba (2014), graduação em Construção de Edifícios pelo Instituto Federal de Educação, Ciência e Tecnologia da Paraíba (2014) e especialização em Gerenciamento de Projetos pela Fundação Getúlio Vargas (2016). Tem experiência profissional na área de Engenharia Civil, com ênfase em Gerenciamento e Execução de Obras.

${ }^{6}$ Arquiteta e Urbanista, graduada pela Universidade Federal da Paraíba (UFPB) (2013) e mestre pelo Programa de Pós-graduação em Arquitetura e Urbanismo da Universidade Federal da Paraíba
} 
RESUMO: A humanidade sempre teve a necessidade de se deslocar de uma localidade para outra à procura de comida e/ou abrigo. Com o passar dos anos, foram descobertas ferramentas para auxiliar na construção de meios de transporte que facilitassem essa mobilidade. Com isso, surgia a necessidade de construir um local que servisse como partida, chegada ou ligação entre um ponto e outro, como por exemplo, os terminais rodoviários. Esses terminais, conhecidos como Rodoviárias, são pontos de apoio aos usuários que fazem uso de transportes coletivos para se deslocar ou até mesmo levar consigo cargas ou objetos. Pensando nisso, o estudo tem a finalidade de desenvolver um Anteprojeto de Reforma e Ampliação do Terminal Rodoviário Adilmar de Paiva Gadelha, na cidade de SousaPB. Metodologicamente, trata-se de uma pesquisa com etapas de revisão bibliográfica, pesquisa de correlatos, levantamento arquitetônico, levantamento fotográfico, e o desenvolvimento do Anteprojeto de Reforma e Ampliação do Terminal Rodoviário de Sousa/PB. O referencial teórico faz menção aos terminais rodoviários, expondo a classificação e a localização dos terminais conforme a literatura, bem como o conforto dos usuários. Por fim, o memorial descritivo detalha o projeto, mostrando desde materiais até procedimentos a serem realizados.

Descritores: Passageiros. Terminal Rodoviário. Transporte.

ABSTRACT: Humanity has always had a need to move from one location to another, searching for food and/or shelter. Over the years, tools have been discovered to assist in the construction of means of transportation that facilitate this mobility. As a result, there arose the need to build a place that could serve as a departure, arrival or connection between one point and another, such as the bus terminals. These terminals, known as Bus Station, are points of support for users who use public transport to move or even carry cargo or objects. With this in mind, the study aims to develop a Reform and Expansion Preliminary Project for the Adilmar de Paiva Gadelha Bus Terminal, in the city of Sousa-PB. Methodologically, this is a research with steps of literature review, correlate research, architectural survey, photographic survey, and the development of the Reform and Expansion Preliminary Project of the Bus Terminal of Sousa/PB. The theoretical framework refers to bus terminals, exposing the classification and location of the terminals according to the literature, as well as the comfort of users. Finally, the descriptive memorial details the project, showing from materials to procedures to be performed.

Descriptors: Passengers. Bus Terminal. Transportation.

(PPGAU-UFPB) (2015). Atualmente é professora do curso de Bacharelado em Arquitetura e Urbanismo da Faculdade Santa Maria - Cajazeiras-PB. Tem experiência ministrando aulas e trabalhando com iniciação científica nos seguintes temas: acessibilidade, mobilidade, avaliação pósocupação, sistema de espaços livres, avaliação pós-ocupação e representação e concepção de projeto. 


\section{INTRODUÇÃO}

Uma das maiores necessidades que surgem com a evolução da humanidade é a de se deslocar de uma localidade para outra à procura de comida e abrigo. Com o passar do tempo, o homem começou a domar a natureza a fim de sanar suas vontades, fabricando trenós ou até mesmo canoas com troncos de árvores, podendo se locomover a distâncias maiores ou carregar objetos mais pesados. Aprendeu a domesticar animais de grande porte para usar como meio de transporte, merecendo destaque a descoberta da roda, o que seria o ponto de partida para mobilidade dos nômades. O homem conseguiu aliar a roda ao animal, e com isso, criar meios de transporte muito mais eficientes e rápidos.

Cidades começaram a se consolidar e, com isso, houve uma crescente necessidade de uso de transportes para fortalecer seus comércios, mas para que isso acontecesse de forma eficiente, era indispensável a implantação de pontos de apoio, parada e encontro de passageiros, surgindo, assim, os terminais rodoviários, que tiveram seu grande marco no Brasil com a criação da Rodovia Presidente Dutra, no ano de 1951, que era responsável por fazer a ligação entre as cidades do Rio de Janeiro e São Paulo (SOARES, 2006).

Os terminais Rodoviários, que são popularmente chamados de Rodoviárias, são pontos de apoio aos usuários que fazem uso de transportes coletivos para se deslocar de um ponto a outro, ou até mesmo levar consigo cargas ou objetos. Estes podem ser utilizados como local de partida, chegada ou ainda simplesmente servir de ligação entre um ponto e outro (SOARES, 2006).

No Brasil, diversos motivos levam à utilização desse serviço, sejam eles em busca de descanso ou lazer, seja por tentativa de melhores condições de trabalho, ou pela pulverização causada pelo aumento das Universidades e Faculdades pelo País (LEMOS, 2007).

Assim, desenvolver um projeto de um Terminal Rodoviário, não se restringe apenas a cálculos estruturais ou projeções geométricas, mas sim ao levantamento 
de um conjunto de variáveis peculiares aqueles que fazem uso deste, os quais devem ser ouvidos como requisito essencial (ALPUIM, 2009).

A cidade de Sousa, localizada na Paraíba, teve sua ascensão e desenvolvimento graças à implantação do transporte ferroviário, que foi responsável por possibilitar o crescimento do comércio e escoamento de grande parte de sua produção de algodão. A implantação da Rede Ferroviária do Nordeste (RFN) iniciouse em 1922, tendo a sua conclusão e início de funcionamento em 1926, ligando Sousa às cidades como Mossoró/RN e Campina Grande/PB; e posteriormente foi desativada totalmente no ano de 2010 (GIESBRECHT, 2018).

O terminal, atualmente, encontra-se em funcionamento, e mesmo com uma alta demanda de serviços, está com sua capacidade produtiva restrita devido a seu precário estado estrutural para funcionamento. As instalações apresentam um mal estado de conservação e deterioração devido ao mal uso e ação do tempo. Destarte, é incontestável a importância do transporte rodoviário para esta cidade, e procurando beneficiar os usuários desses serviços, buscando torná-lo um local seguro e funcional, o presente trabalho procura propor um Anteprojeto de Reforma e Ampliação do Terminal Rodoviário Adilmar de Paiva Gadelha na cidade de Sousa na Paraíba.

\section{METODOLOGIA}

A metodologia empregada neste trabalho foi de natureza aplicada, porque está voltada para a solução de dado problema, que é a reforma e ampliação do terminal rodoviário de Sousa/PB. Baseada na abordagem qualitativa e objetivo exploratório, com o intuito de explorar os problemas e potencializadas do espaço. Diante disso, as etapas metodológicas foram divididas em Pesquisa bibliográfica, projetos correlatos, levantamento arquitetônico, levantamento fotográfico, diretrizes projetuais e desenvolvimento do anteprojeto. 
A pesquisa bibliográfica abrange a verificação e compreensão da investigação do tema abordado, realizando a pesquisa em legislações vigentes, livros, teses e órgãos municipais e estaduais.

Em visita ao terminal, foi feito um levantamento fotográfico onde os arquivos registrados foram utilizados em análises e em posterior durante o desenvolvimento do trabalho.

A última etapa foi a de desenvolvimento do anteprojeto, onde foram definidos os aspectos funcionais e estéticos do novo terminal rodoviário. O anteprojeto foi apresentado através de desenhos técnicos como plantas, cortes, fachadas e perspectivas, além do memorial descritivo, finalizando assim o processo projetual.

A cidade de Sousa está localizada no vale do piranhas na região do alto sertão da Paraíba. O acesso principal é pela rodovia federal BR-230, atravessando todo o Estado de leste a oeste e cruzando algumas das maiores cidades do estado como Campina Grande e Patos.

Localizado na entrada da cidade, para quem vem no sentido leste, o terminal rodoviário foi construído em uma área onde o fluxo de transportes que fossem transitar naquela localidade não influenciasse diretamente na malha urbana, de modo a causar congestionamentos indesejados como também impactos maiores na configuração já existente.

Na figura 1, é possível perceber que existe uma circulação exclusiva para os ônibus transitarem até o terminal, fazendo com que esse fluxo não venha a obstruir nenhuma via que esteja próxima a edificação. A área de entorno é contemplada por alguns espaços importantes da cidade que são locais de intensa movimentação, entre eles temos o Hospital Regional, órgãos públicos (fórum, justiça federal e ministério público), praça pública, SESI e até mesmo uma habitação popular que foi criada com o passar dos anos de forma irregular, mesmo assim nenhum dos locais é prejudicado pela inserção do terminal no local. 
Figura 1 - Mapeamento da análise do entorno.

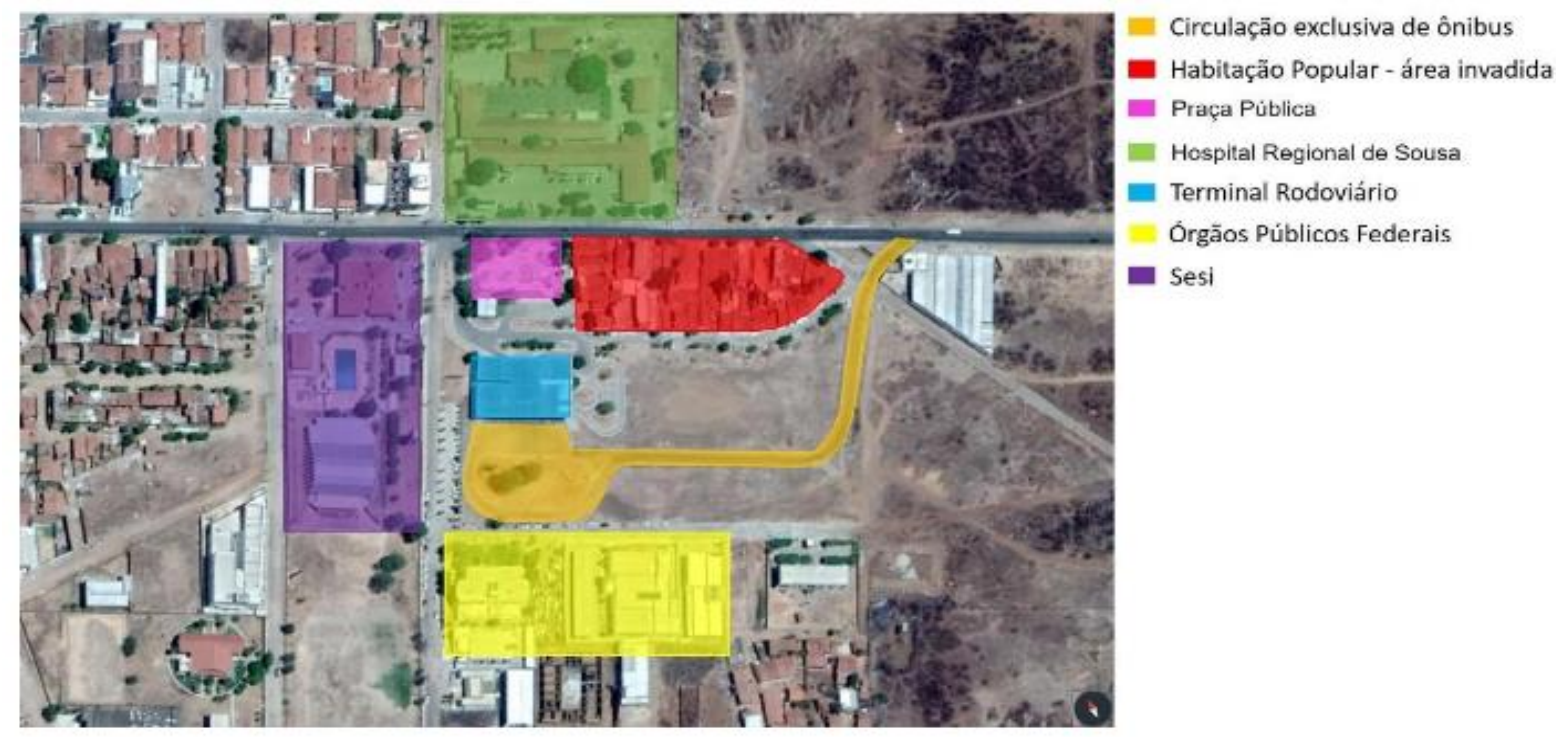

Fonte: Google Mpas (2019). Editado pelo autor.

O pavimento térreo é configurado pelos seguintes setores: setor de vivência, onde fica localizados circulação de rampas, espaço de espera e os sanitários; setor administrativo, local de apoio que dá suporte à funcionários das empresas de ônibus como também à funcionários do terminal, e por último, o Setor Comercial que é toda parte de Guichês para a venda de passagens e os boxes de serviços gerais.

Com o intuito de registrar a atual situação do terminal rodoviário, foi realizado um levantamento fotográfico no dia 18 de março de 2019 com o intuito de perceber e posteriormente analisar melhor os espaços existentes. 
Tabela 1 - Levantamento Fotográfico.

\begin{tabular}{|l|l|}
\hline \multicolumn{1}{|c|}{ FOTOGRAFIAS } & \multicolumn{1}{|c|}{ COMENTÁRIOS } \\
\hline & $\begin{array}{l}\text { A fachada principal do terminal } \\
\text { rodoviário (norte), por onde a maioria } \\
\text { dos usuários que vem a pé ou de } \\
\text { carro de pequeno porte acessam o } \\
\text { terminal. }\end{array}$ \\
\hline
\end{tabular}

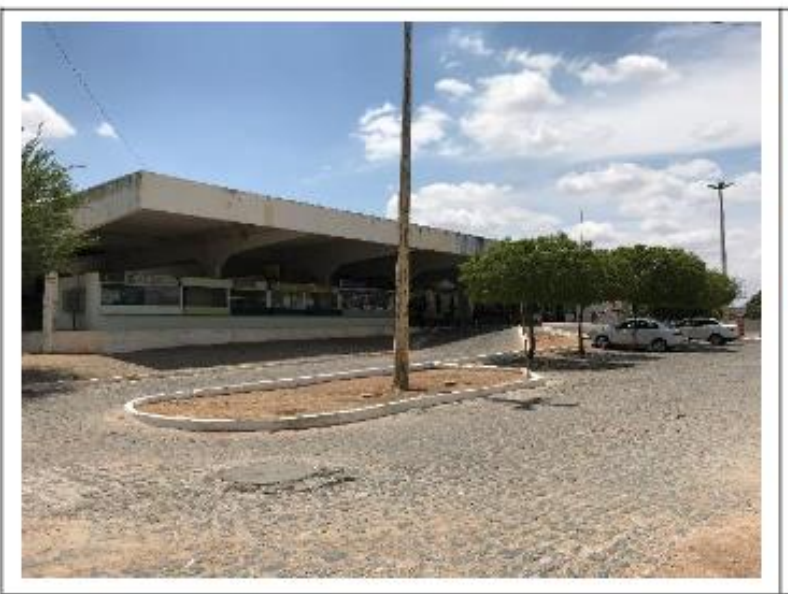

Em outra vista da fachada principal é possível observar as poucas vagas existente para estacionamentos de taxi.

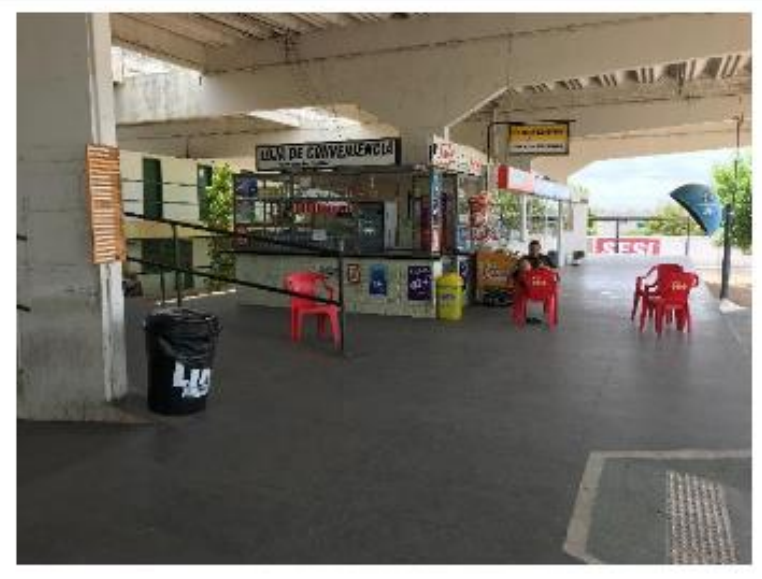

Ao lado direito da entrada do terminal ficam localizados os boxes, alguns ainda vazios. 

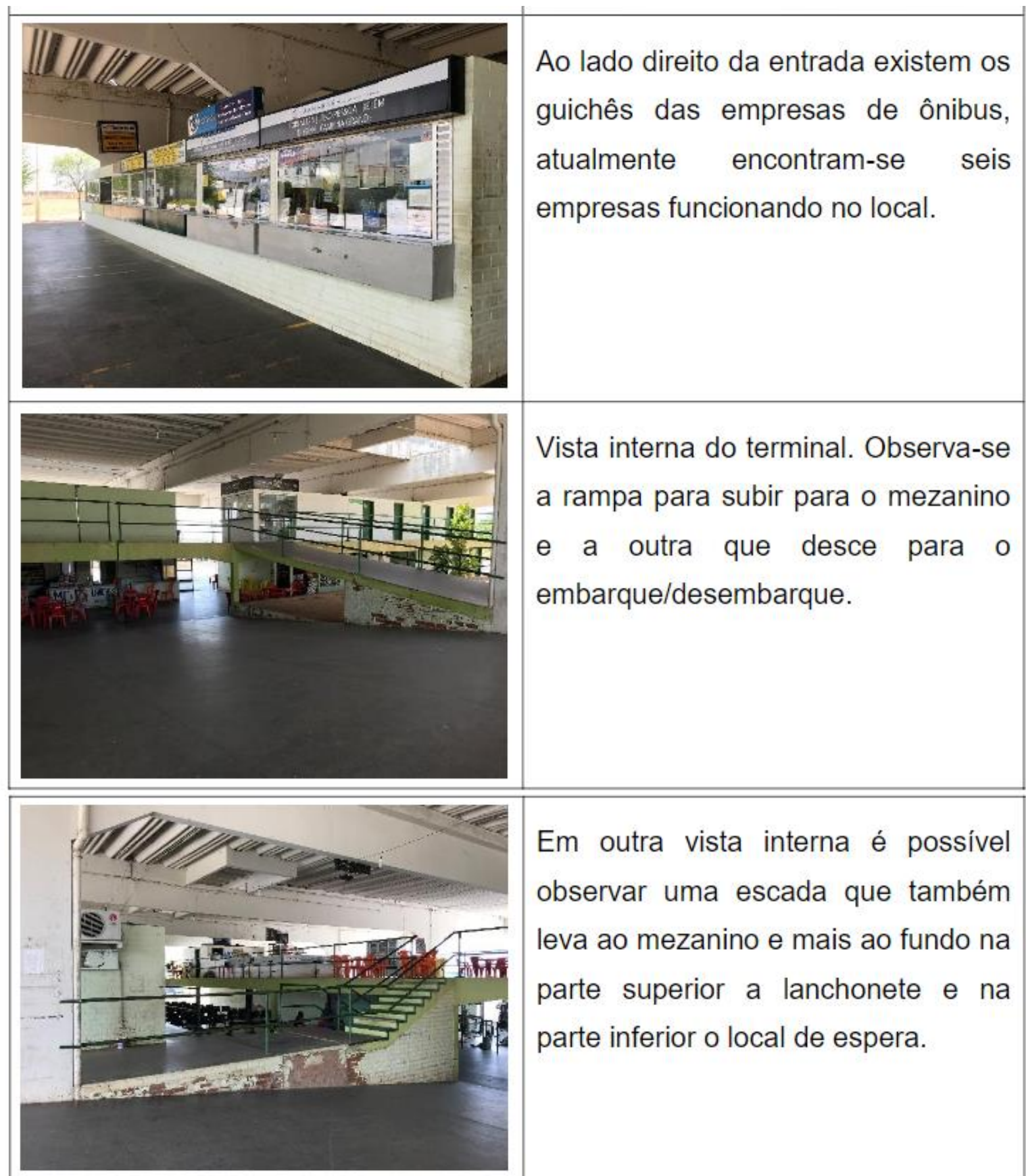

Em outra vista interna é possível observar uma escada que também leva ao mezanino e mais ao fundo na parte superior a lanchonete e na parte inferior o local de espera.

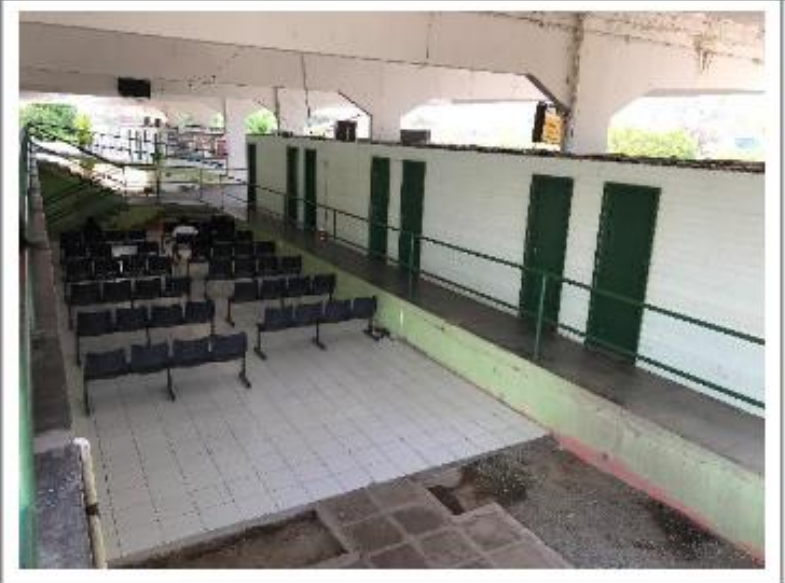

Local de espera em um ângulo diferente. Nota-se que esse espaço foi adaptado, antes aqui existia um espaço destinado a área verde. 


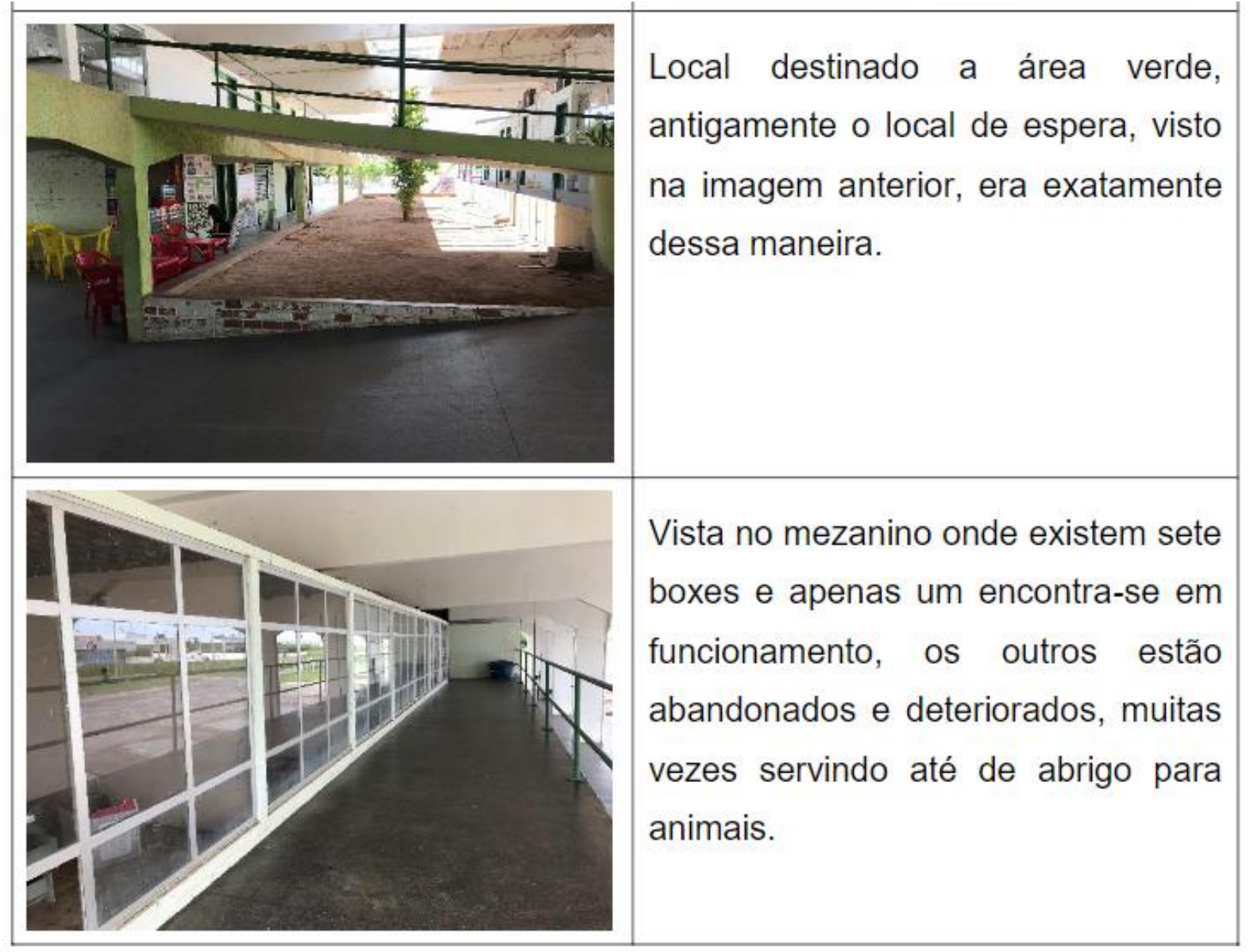

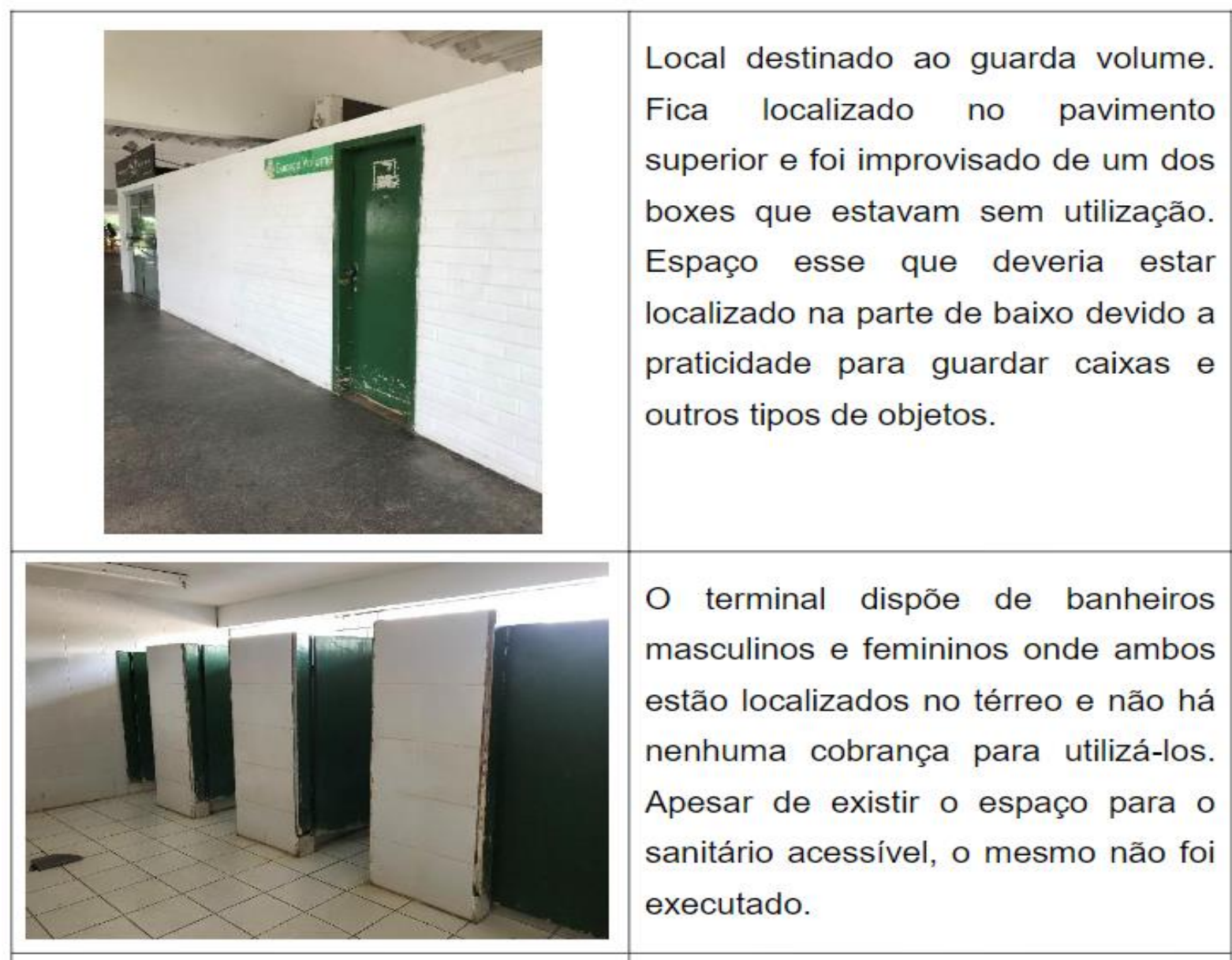



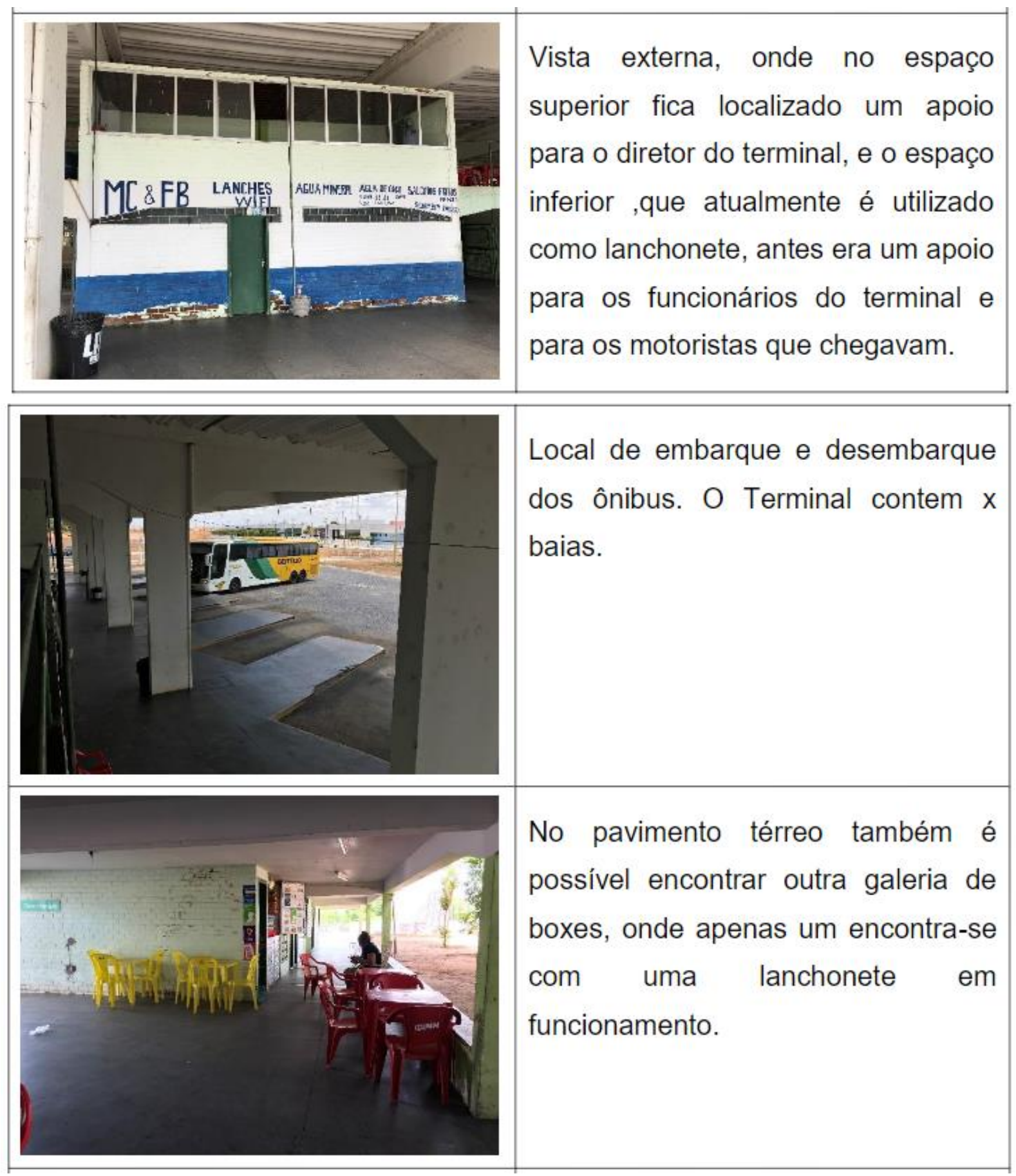


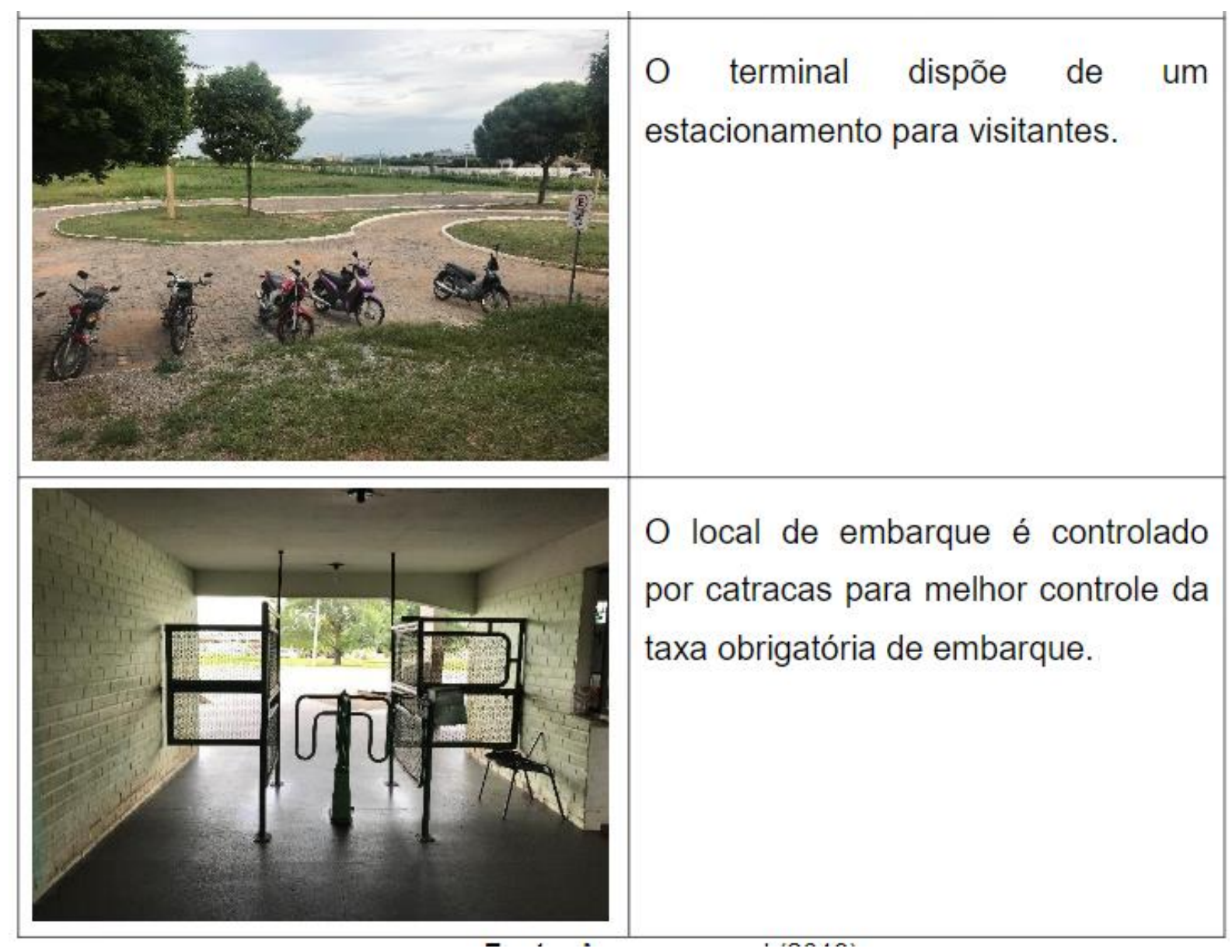

Fonte: Acervo pessoal (2019).

\section{RESULTADOS E DISCUSSÃO}

Foram realizados estudos e pesquisas de projetos para a elaboração da proposta apresentada. Estes trabalhos auxiliaram na criação do repertorio para desenvolver o projeto, como também nas soluções adotadas ao longo do trabalho. As referências usadas têm como objetivo escolher projetos que englobem o programa arquitetônico e se assemelhem ao que será desenvolvido quanto ao uso e demais funcionalidades.

O Terminal Rodoviário Severino Camelo, concebido pelos arquitetos Glauco Campello e José Luiz Franca de Pinho em 1976, constitui uma obra representativa do moderno brasileiro na cidade de João Pessoa em suas qualidades 
plásticoformais e espaciais, além de materializar os princípios de adequação da arquitetura ao clima (quente-úmido) e à paisagem natural e urbana (ROCHA, 2012).

$\mathrm{Na}$ área livre que circunda o edifício, articulam-se os acessos, as vias internas e os estacionamentos numa disposição que evita o cruzamento de seus fluxos e a interferência danosa no sistema viário do entorno imediato. Em vermelho, o acesso de veículos; em azul, o acesso de pedestres; em verde, o acesso dos ônibus; em amarelo, a saída de veículos e em magenta, a saída de ônibus (ROCHA, 2012).

Figura 2 - Implantação no lote com indicações de acessos.

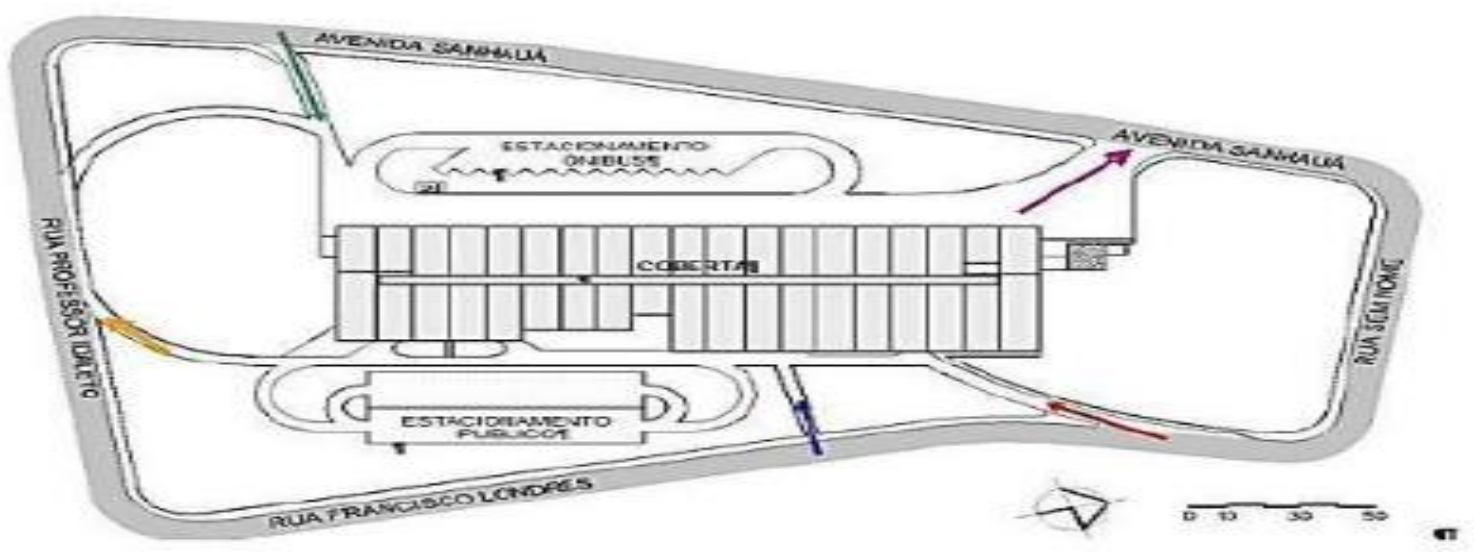

Fonte: Rocha (2012).

O embasamento da edificação em diferentes níveis, tirando partido da inclinação natural do terreno, atende ao princípio moderno de economia e racionalização. Essa base da edificação em níveis interligados por rampas, aliada ao partido longitudinal adotado, facilita a distribuição linear dos diversos setores, permitindo a apreensão rápida e geral do espaço do Terminal pelo usuário quando este chega à área de embarque através do nível $+1,30$, sendo esta uma das grandes qualidades de sua proposta arquitetônica (ROCHA, 2012).

Para o seguinte trabalho, foram pesquisadas normas da ABNT, assim como leis do código de obra do município de Sousa/PB.

Em relação à acessibilidade, empregou-se a NBR 9050/2015 que define aspectos relacionados às condições de acessibilidade no meio urbano. Portanto, serão estabelecidos critérios e parâmetros técnicos a serem observados quando do 
projeto, construções, instalação e adaptação de edificações, espaços e equipamentos urbanos às condições de acessibilidade (inclusão).

Referente às especificações do código de obra do município, ficam definidos de acordo com lei municipal 949 de 10 de abril de 1980, no Livro II das obras, Título I.

A definição do conceito do anteprojeto parte da ideia de movimento e funcionalidade. O terminal rodoviário é um ambiente de grande fluxo de pessoas e veículos, dessa maneira, o anteprojeto busca proporcionar maior agilidade na utilização dos ambientes, como também um melhor aproveitamento dos espaços.

Os espaços foram definidos de maneira que, além de priorizar os fluxos e o desempenho do terminal, eles conseguissem preencher ambientes que se encontram em desuso. Dessa forma, os ambientes de estacionamentos, espera, sanitários, box, rampas, apoios, guarda volume e áreas verdes foram reorganizados trazendo melhor qualidade aos ambientes.

Atualmente, o terminal rodoviário conta com oito vagas de estacionamentos para clientes e nove vagas para os taxistas, a proposta dispõe tem 32 vagas para estacionamentos de usuários, sendo cinco para pessoas idosos, cinco para PCD e 22 para as demais e também 15 vagas de estacionamentos para motos. O anteprojeto inclui uma estrutura em caramanchão de madeira com arborização para o sombreamento do espaço e maior comodidade do ambiente. (Figuras 3 e 4). 
Figura 3 - Proposta dos estacionamentos - Taxis e PCD.

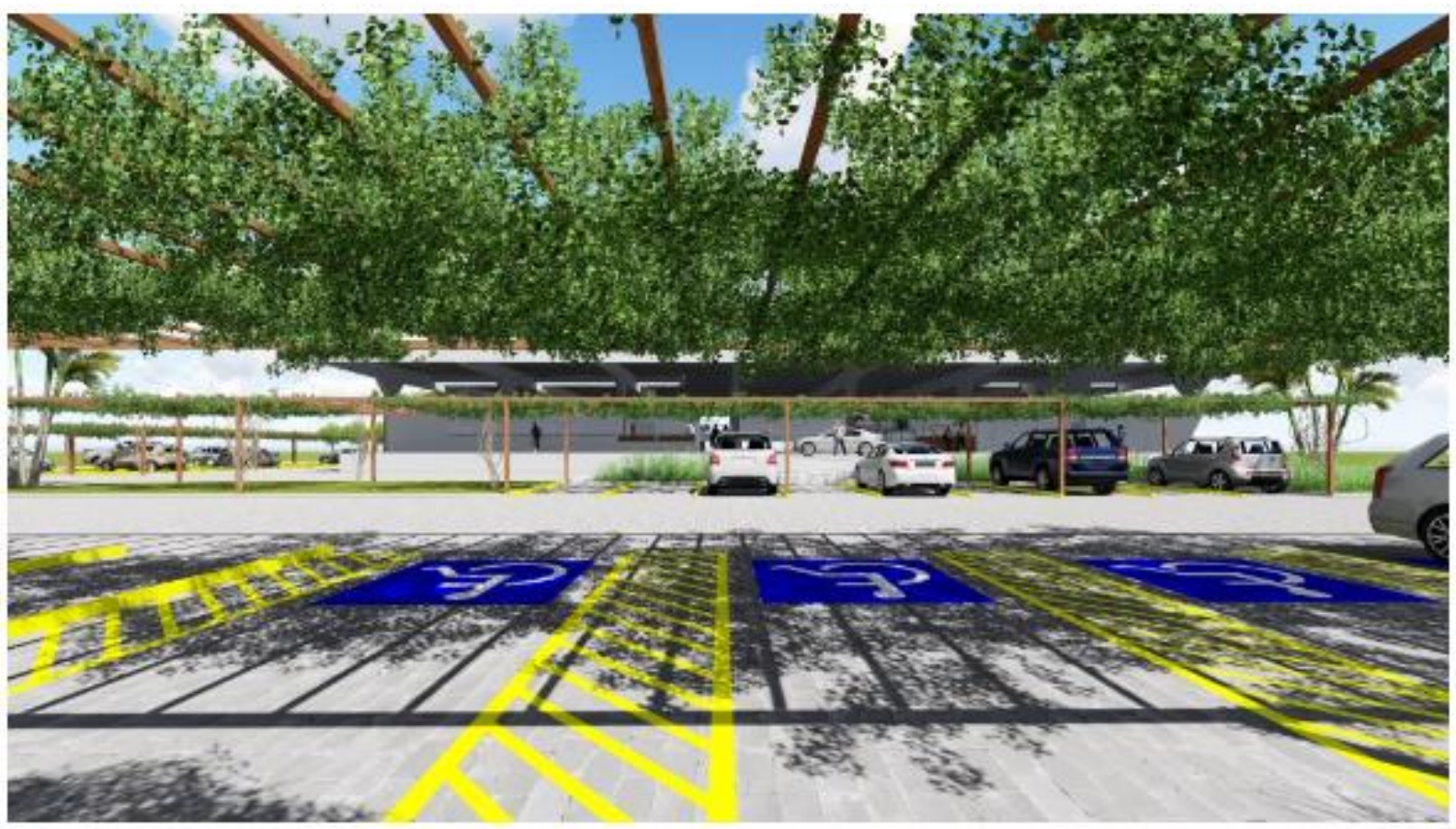

Fonte: Elaborado pelo autor (2019).

Figura 4 - Proposta dos estacionamentos - Usuários.

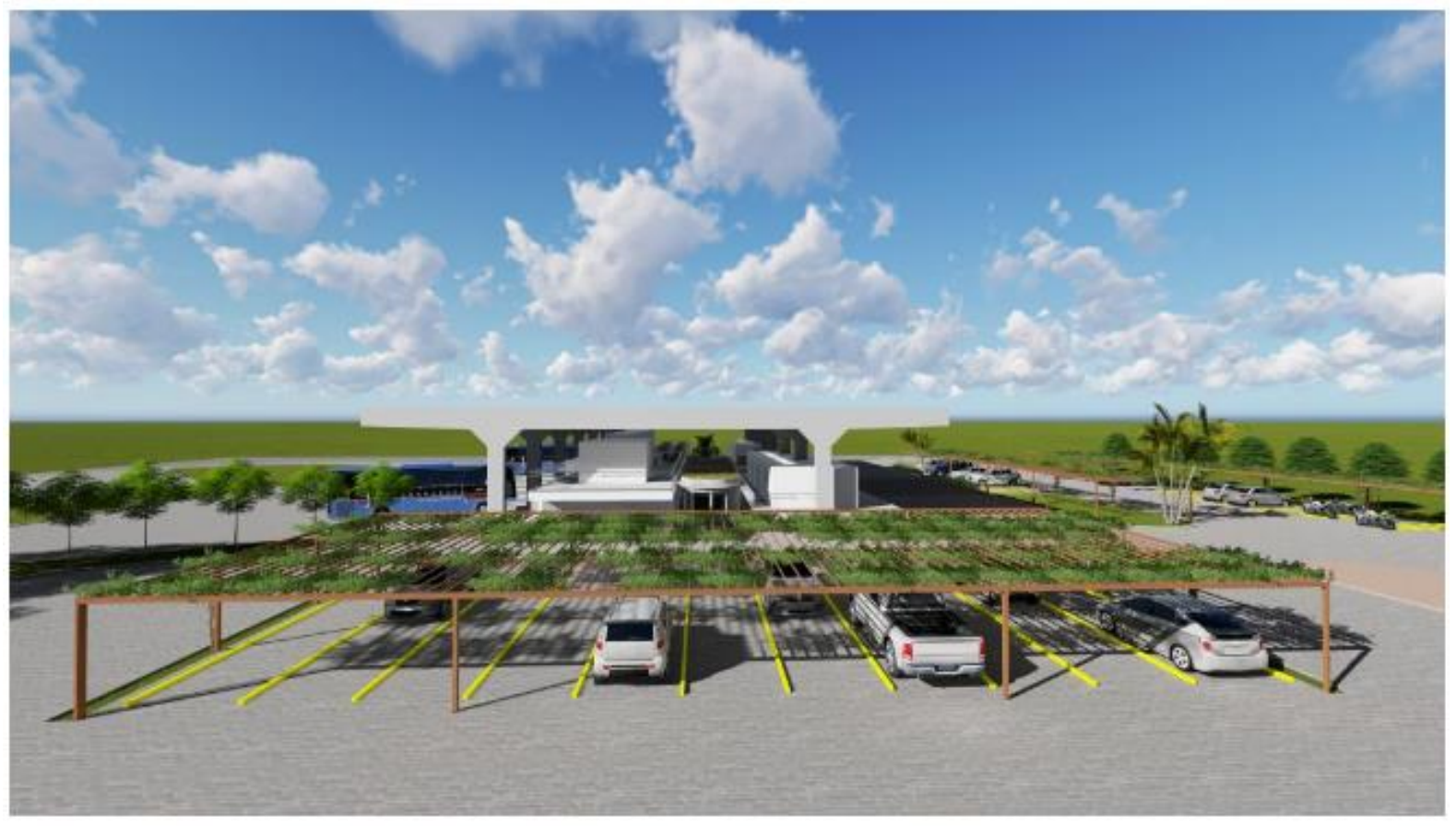

Fonte: Elaborado pelo autor (2019). 
Considerando as rampas existentes no terminal, foram analisadas as inclinações conforme a NBR 9050 e feitas as devidas alterações para que ficassem acessível a todos. A rampa que dá acesso aos taxis estava com inclinação de $29 \%$, não havendo possibilidades para PCD transitarem sozinhos. Com a nova proposta, a rampa adquiriu inclinação de $8 \%$ e também foram adicionados corrimões em inox, aumentando a segurança e trazendo maior comodidade. (Figura 5).

Figura 5 - Proposta de rampa para acesso a taxis.

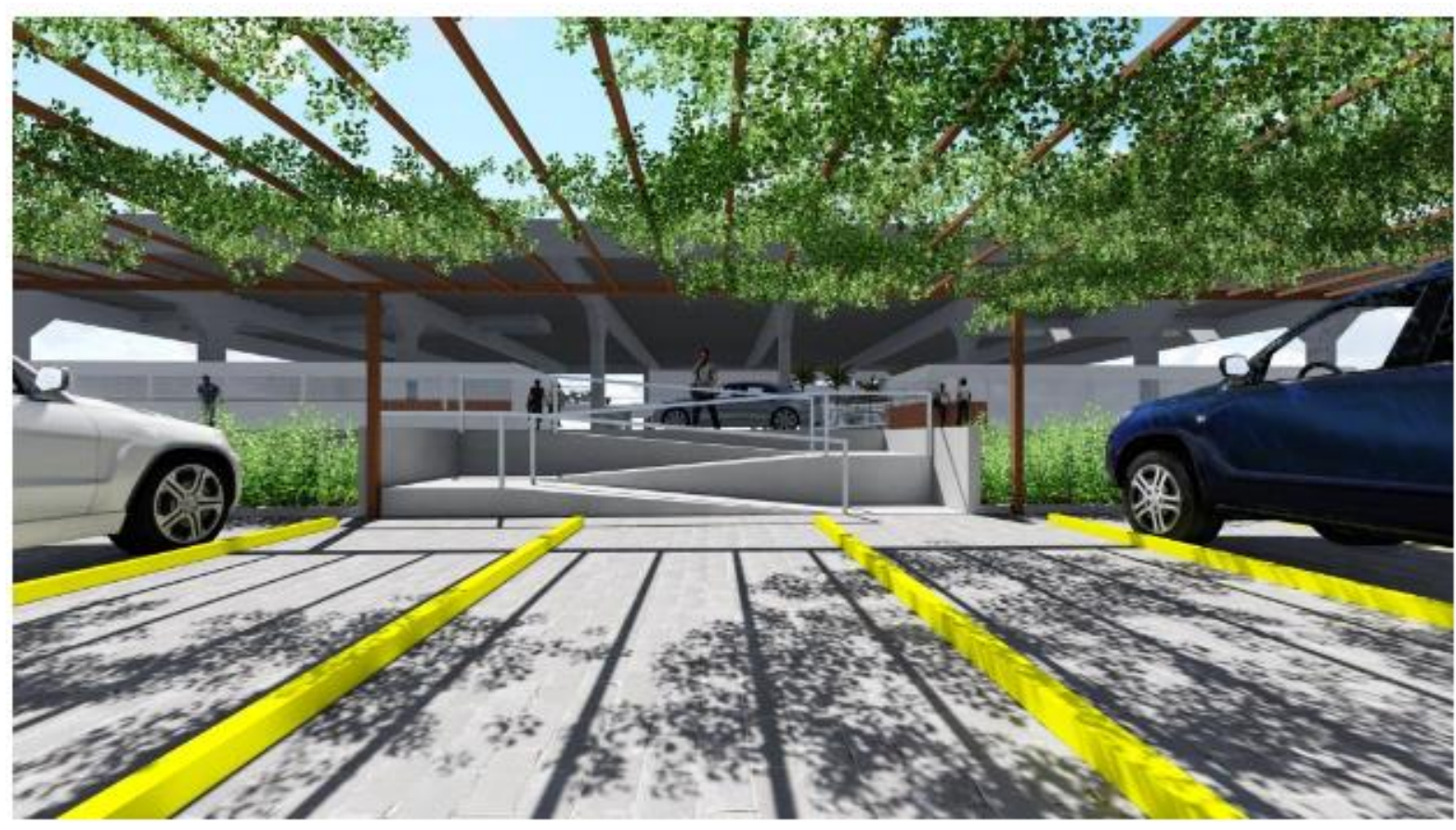

Fonte: Elaborado pelo autor (2019).

$\mathrm{Na}$ parte interna da edificação, a rampa que dá acesso ao mezanino encontra-se com inclinação de 16\%, e, mais uma vez, não segue a NBR 9050. A Figura 6 mostra a nova proposta para a rampa que passaria a ter inclinação de $8,33 \%$ um jardim central e guarda corpo em vidro e inox. 
Figura 6 - Proposta rampa de acesso ao mezanino.

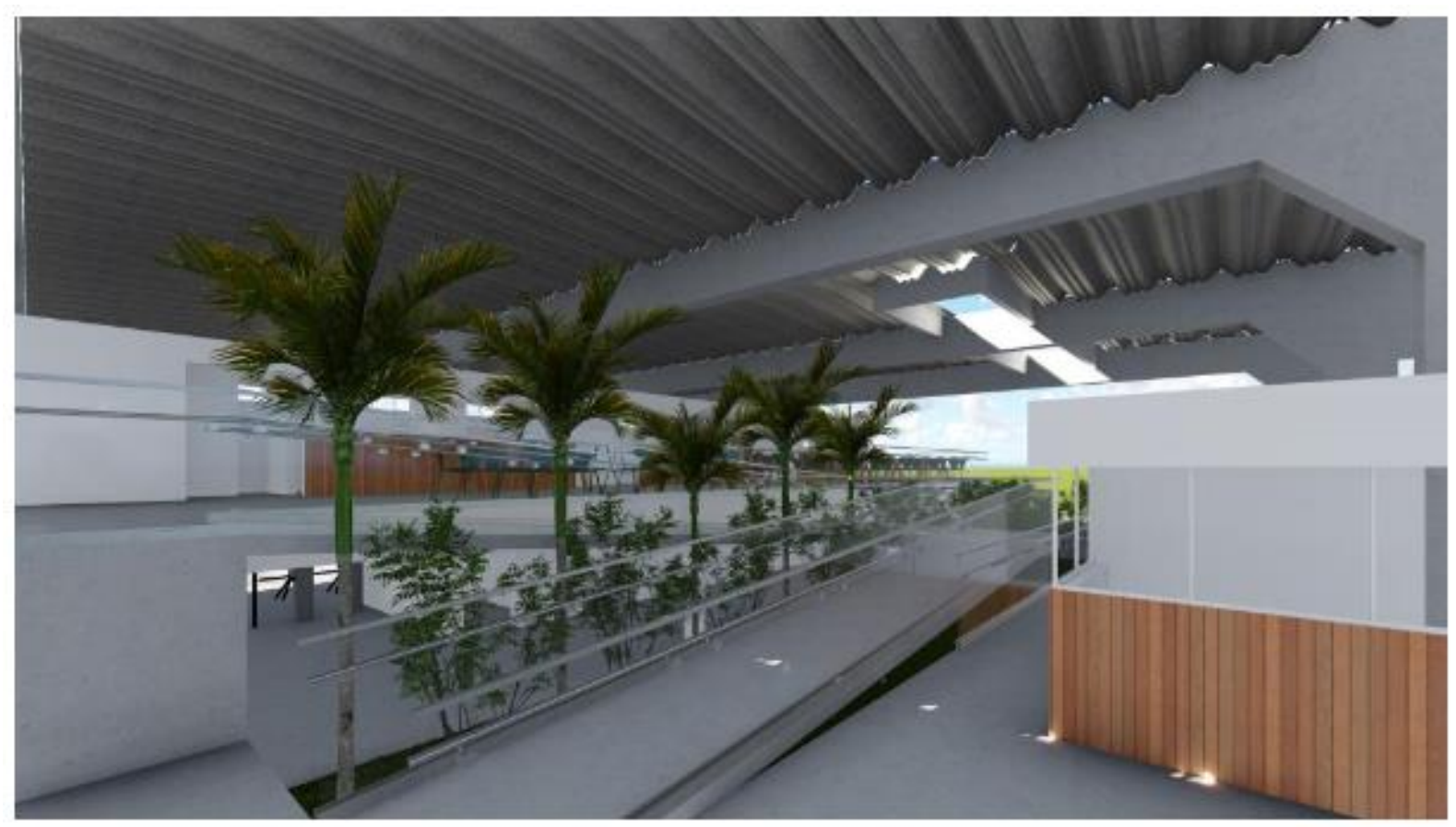

Fonte: Elaborado pelo autor (2019).

A estrutura da coberta é composta por concreto armado com telhas kalhetão de fibrocimento (Figura 6). As telhas de fibrocimento são produzidas com cimento reforçado e fios de sintéticos (CFRS), seguem as normas da NBR 15210, que caracteriza as telhas de fibrocimento ondulada sem amianto, tendo uma maior durabilidade e fácil manuseio, sendo indicadas para cobertura de grandes vãos e com inclinação mínima de $9 \%$. Na figura 7 , pode-se observar que foi feita uma diminuição em uma das aberturas existentes devido às alterações feitas na parte interna da edificação. 
Figura 7 - Telhão kalhetão de fibrocimento.

Fonte: Brasilit (2019).

Para contribuir com o meio ambiente, optou-se pelo teto verde na cobertura dos quiosques e lojas. O teto verde ajuda a equilibrar a temperatura do ambiente interno abaixo da abertura existente na coberta, podendo assim receber luz solar e águas decorrentes das chuvas.

A estrutura do teto será executada de acordo com a tecnologia da Sky Garden - Paisagismo sustentável, seguindo o passo a passo do manual e especificação técnica do sistema de telhado verde. 
Figura 8 - Passo a passo da montagem do teto verde.

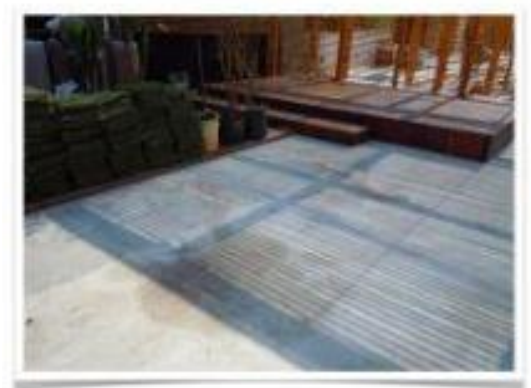

1. Laje impermeabilizada préexistente

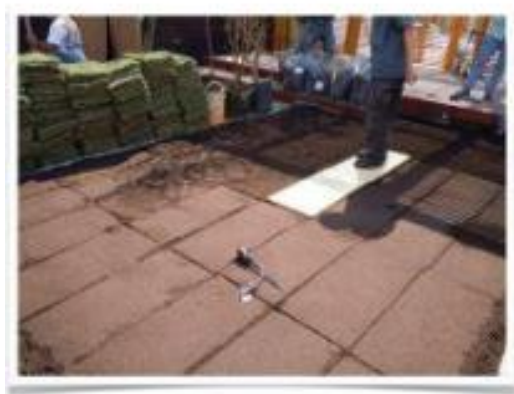

4. Aplicaçăo do substrato em camada na espessura desejada

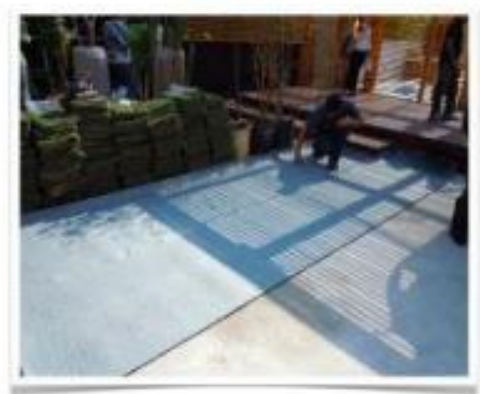

2. Aplicação da manta geodrenante e/ou bidim

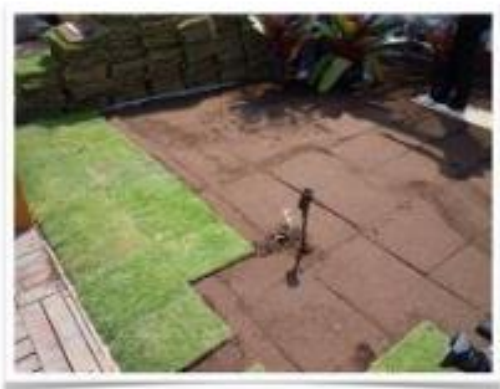

5. Plantio da vegetaçăo convencional.

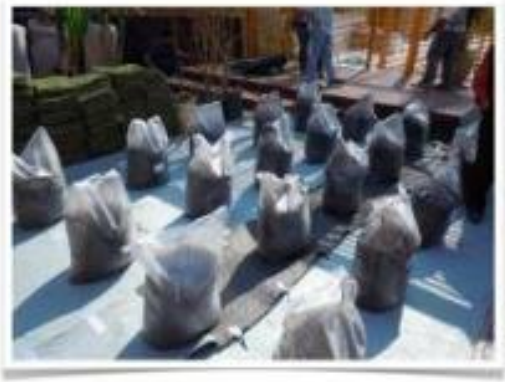

3. Posicionamento das embalagens de substrato

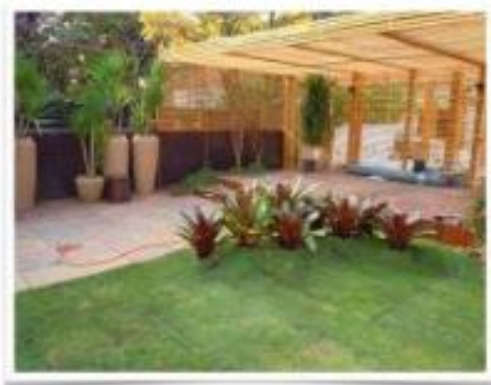

6. Aparência imediata pósplantio.

Fonte: Sky Garden (2019).

Segundo a Sky Garden, podem ser realizados projetos de paisagismo complexo no telhado verde, com forrações, flores, arbustos e até arvores, dependendo da espessura (figura 24). Nesse caso, seriam utilizadas plantas floríferas, as quais têm raízes menores e configurariam um jardim para as pessoas que estiverem no pavimento mezanino, onde poderão apreciar o espaço verde (figura 9). 
Figura 9 - Corte esquemático.

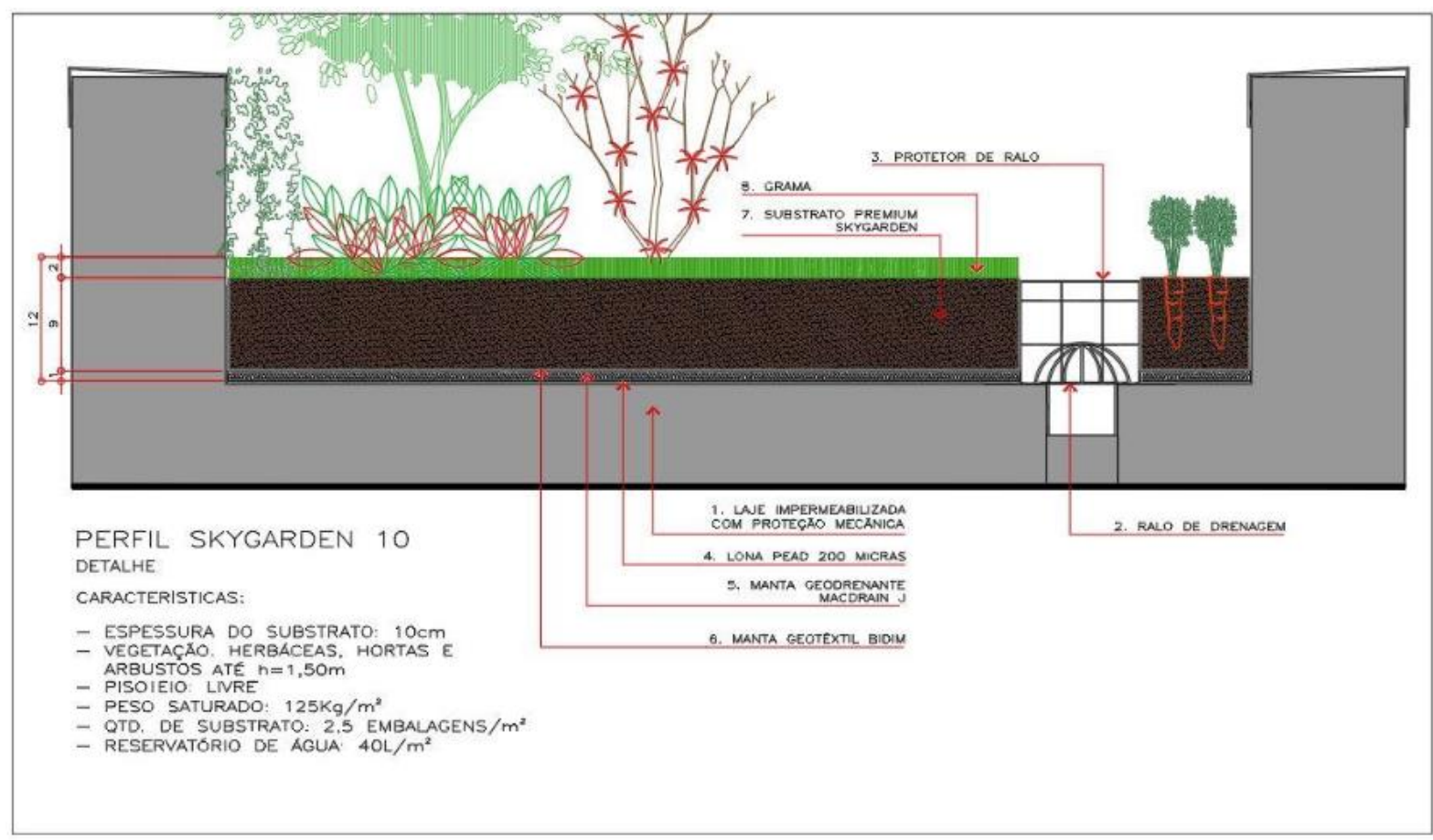

Fonte: Sky Garden (2019).

Figura 10 - Proposta do teto verde.

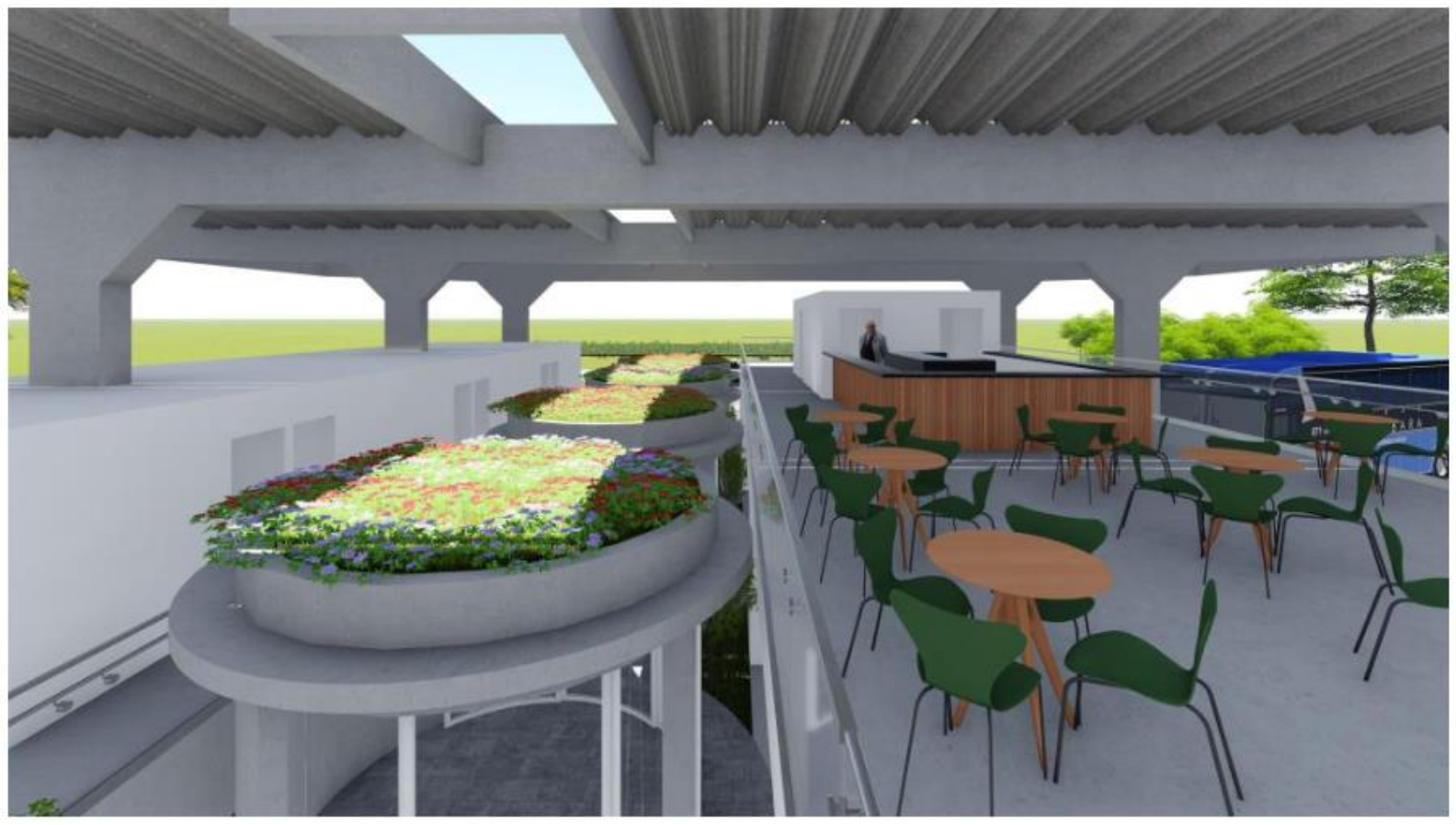

Fonte: Elaborado pelo autor (2019). 
Localizada nas áreas internas e externas as áreas verdes inseridas no terminal rodoviário trazem arborização bastante comum na região. Para as áreas externas foram utilizadas as trepadeiras bouganville nos caramanchões, gramas esmeraldas, nim indiano e palmeiras areca (figura 10) foram utilizadas também em áreas externas em locais específicos que pudessem ornamentar e trazer sombreamento.

Nas áreas internas, o paisagismo foi utilizado no teto verde dos quiosques e lojas, como também na abertura existente entre as rampas de acesso ao mezanino e em outras áreas. As espécies utilizadas para o teto verde foram as floríferas amor perfeito (figura 11), que trazem flores de diversas cores, cujas raízes não são extensas. As escolhas das plantas floríferas foram feitas com intuito de criar um jardim que pudesse ser contemplado no momento em que as pessoas estivessem no mezanino.

Figura 11 - Arborizações utilizadas.

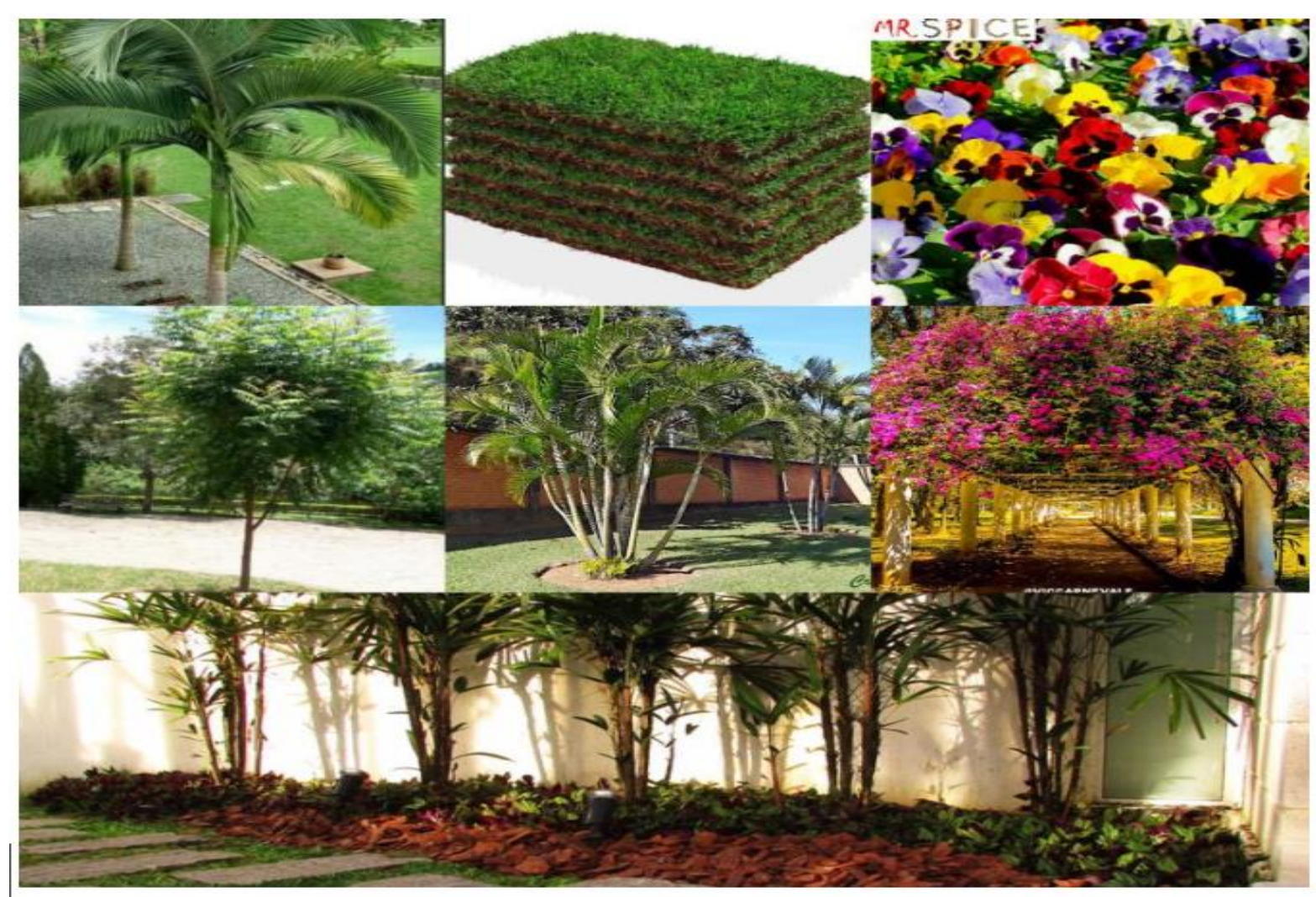

Fonte: Flora delivery (2019). 
Todas as paredes externas e internas serão emassadas, lixadas e pintadas com tinta acrílica semibrilho na cor branco neve.

O piso será em granilite na cor cinza, que possui aspecto próximo ao granito natural, é de fácil manutenção, tem alta durabilidade e baixa custo. Após aplicação, o piso é polido e recebe camadas de impermeabilizantes à base de água ou solventes para trazer um acabamento brilhante espelhado e proteção contra sujeiras e outros produtos que possam danificar o piso.

Figura 12 - Proposta embarque/desembarque.

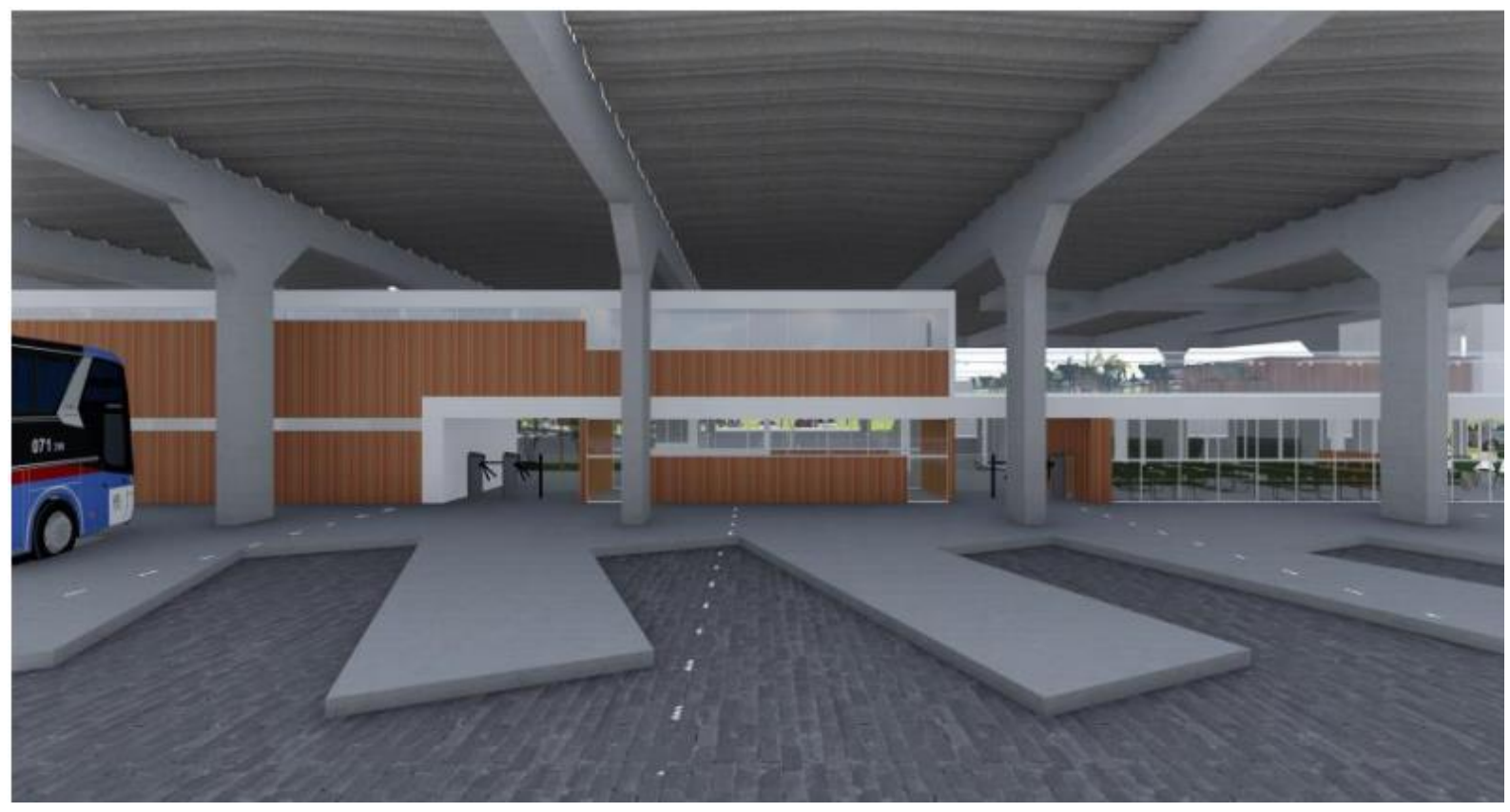

Fonte: Elaborado pelo autor (2019). 
Figura 13 - Café/Local de espera.

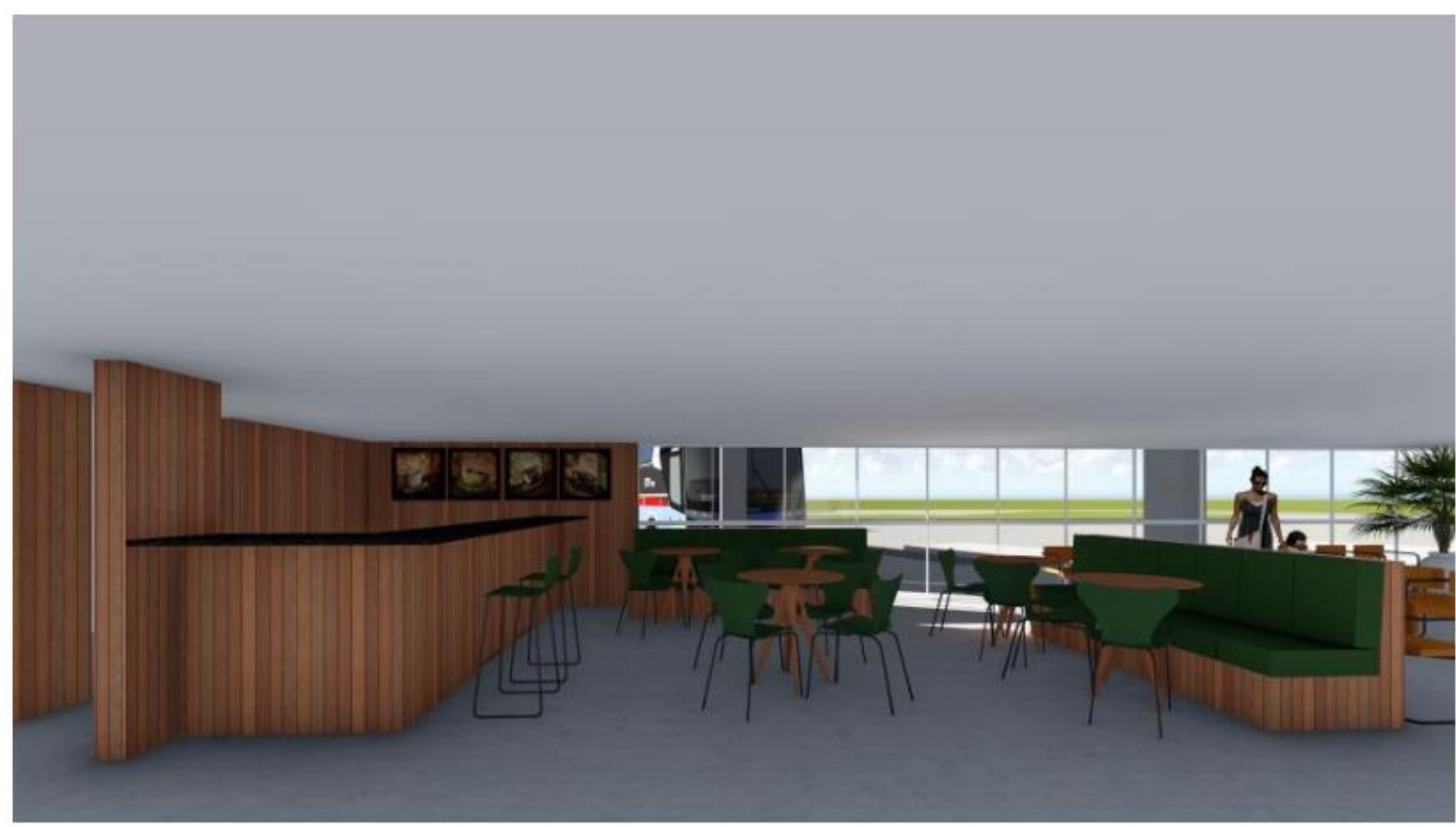

Fonte: Elaborado pelo autor (2019).

Utilizados nas áreas externas como elemento de vedação, os cobogós ajudaram a garantir a iluminação e ventilação natural. Os elementos estão localizados nas fachadas leste e oeste e são peças fabricadas em concreto com $40 \times 40 \times 10 \mathrm{~cm}$ e pintados na cor branco gelo com tinta acrílica. 
Figura 14 - Cobogós.

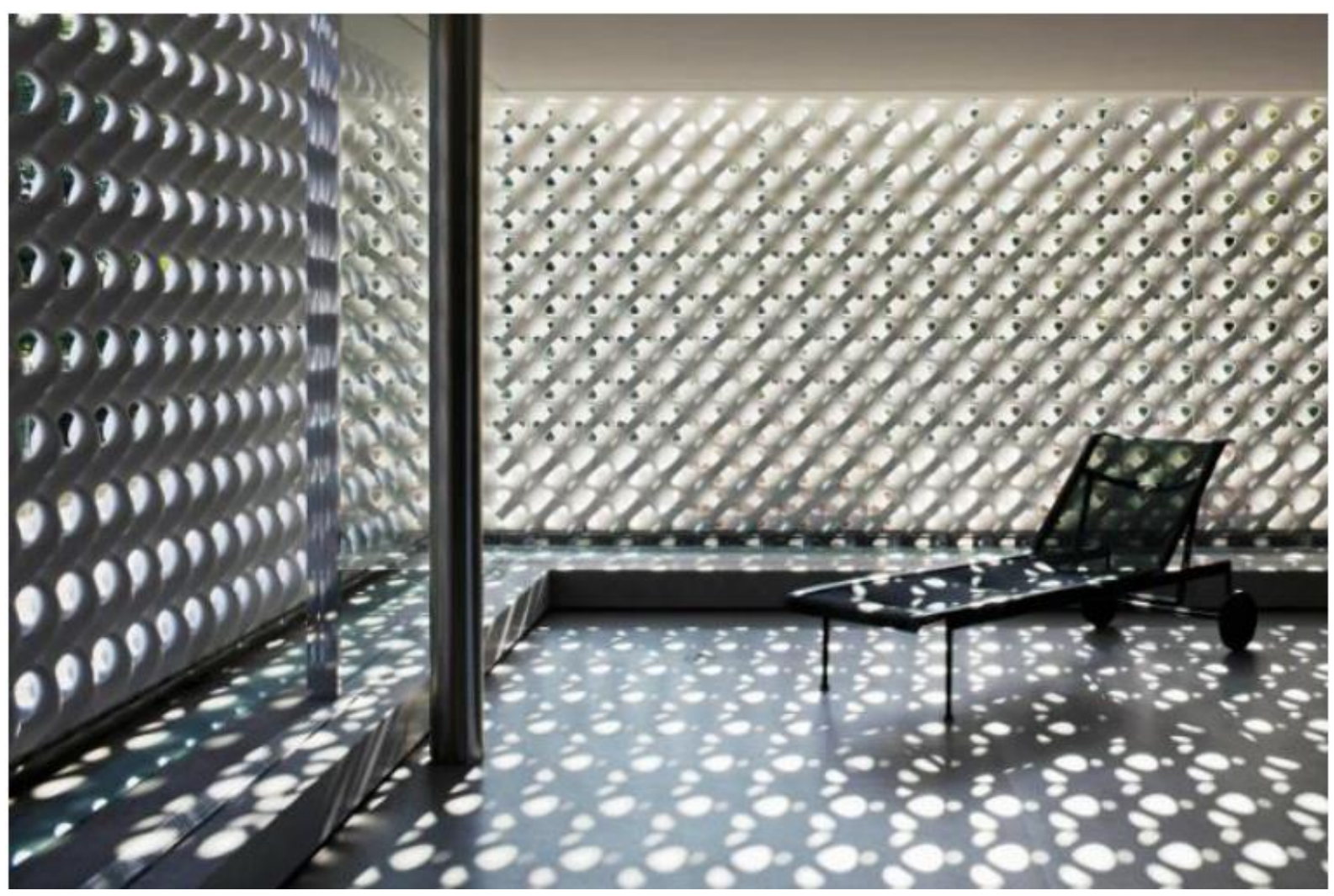

Fonte: Casa Show (2015).

As janelas boca de lobo fixadas nos banheiros seguiram o dimensionamento do quadro de esquadrias e serão em vidro temperado jateado com espessura mínima de $8 \mathrm{~mm}$ e perfis de alumínio natural que podem variar entre 3 e $5 \mathrm{~cm}$, de acordo com o fabricante. Já as janelas boca de lobo localizadas nas salas do mezanino serão em vidro temperado transparente e seguem as mesmas espessuras tanto do vidro quanto do alumínio.

Existirão três tipos de portas: as de madeiras, de vidro e de alumínio, que, assim como as janelas, seguiram as dimensões especificadas no quadro de esquadrias.

As portas de madeira de giro deverão ter espessura mínima de $35 \mathrm{~mm}$ em madeira maciça, revestidas com compensado de $3 \mathrm{~mm}$ e pintadas com verniz incolor para dar brilho e manter o aspecto natural. 
As portas de vidro temperados transparentes terão espessura mínima de $8 \mathrm{~mm}$ e as portas de alumínio na cor natural e espessura de $30 \mathrm{~mm}$.

\section{CONSIDERAÇÕES FINAIS}

Para o desenvolvimento do trabalho, buscou-se produzir um anteprojeto de reforma e ampliação do terminal rodoviário Aldimar de Paiva Gadelha na cidade de Sousa/PB. As premissas usadas na escolha do tema embasaram-se na necessidade de ter um terminal com maior funcionalidade e melhor estrutura do que 0 atual.

O objetivo foi desenvolver um projeto que tivesse como prioridade o conforto dos usuários, a funcionalidade e que fosse capaz de aproveitar espaços que se encontram em desuso e deixam o terminal, em partes, com áreas desocupadas.

Assim, para melhor embasamento, a revisão bibliográfica sobre terminais rodoviários foi de suma importância, como também as visitas em loco. O projeto que foi proposto nesse trabalho visa a buscar uma estrutura que priorize os fluxos, trazendo a união do conforto e o melhor aproveitamento de espaços existentes.

Ao adentrar nesse assunto, foi possível descobrir que o terminal rodoviário Adilmar de Paiva Gadelha estará em breve passando por reformas, sendo assim, trabalhos como esse podem ser apresentados à prefeitura da cidade para ajudar na elaboração de novas ideias, ajudando a beneficiar ainda mais essa edificação que é de uso coletivo.

Portanto, ao finalizar esse trabalho, é possível perceber que o principal objeto foi criar um anteprojeto capaz de agregar valores ao terminal ao mesmo tempo que proporciona espaços com maior conforto, qualidade e segurança a todos que utilizam dos serviços. 


\section{REFERÊNCIAS BIBLIOGRÁFICAS}

AFONSO, A G. et al. Modais de Transporte. Faculdade Anhanguera Jaraguá do Sul. 2018.

ALPUIM, F. A. C. G. Terminal Rodoviário de Passageiros. 2009. 130 f. Dissertação (Mestrado em Engenharia Civil) - Departamento de Engenharia Civil, Faculdade de Engenharia da Universidade do Porto. Porto, 2009.

ARRUDA, P. C. Novo Terminal Rodoviário para o município de Marataízes-ES. 2013. 77 f. Monografia (Graduação em Arquitetura e Urbanismo) - Instituto Federal de Educação, Ciência e Tecnológica Fluminense. Campos dos Goytacazes, 2013.

COSTA, M. F. H. Uso de Modelos de Localização para o Diagnóstico de Rede de Terminais de Transporte de Passageiros - Estudo de Caso em Terminais Rodoviários do Estado do Ceará. 2010. 89 f. Dissertação (Mestrado em Engenharia de Transportes) Universidade Federal do Ceará. Fortaleza, 2010. Disponível em: <http://repositorio.ufc.br/bitstream/riufc/574/1/2010_dis_mfhcosta.pdf>. Acesso em 16 nov 2018.

FERRAZ, A. Além do Rio: uma fotografia da paisagem urbana de Sousa - Paraíba. 2 ed. Sousa: AGT Produções, 2011.

DESCONHECIDO. Flora delivery. Disponível em: <https://www.floradelivery.com.br/rafis>. Acesso em: 17 maio 2019

GIESBRECHT, R. M. Rede de Viação Cearense (1926-1975). 2018. Disponível em: <http://www.estacoesferroviarias.com.br/ce_crato/souza.htm>. Acesso em: 11 nov. 2018.

GOOGLE MAPS. Terminal Rodoviário da Cidade de Sousa/PB - Adilmar de Paiva Gadelha. 2018. Disponível em: <https://www.google.com/maps/place/Rodovi\%C3\%A1ria/@-6.7649865,$8.2219195,385 \mathrm{~m} / \mathrm{data}=! 3 \mathrm{~m} 1 ! 1 \mathrm{e} 3 ! 4 \mathrm{~m} 5 ! 3 \mathrm{~m} 4 ! 1 \mathrm{~s} 0 \times 7 \mathrm{a} 45 \mathrm{bee} 3 \mathrm{caed} 7 \mathrm{ab}: 0 \times$ xead63b71c624cd95!8m2! 3d-6.765472!4d-38.2209588?hl=pt-BR>. Acesso em 17 nov 2018.

GIL, A. C. Como Elaborar Projetos de Pesquisa. 5 ed. São Paulo: Atlas, 2010.

LEMOS, A. M. B. Portais Urbanos - Rodoviários. 2007. 159 f. Dissertação (Mestrado em Arquitetura) - Faculdade de Arquitetura, Universidade Federal do Rio Grande do Sul. Porto Alegre, 2007.

PLATE, Master. PISO GRANILITE. Disponível em: <https://www.masterplate.com.br/pisogranilite/>. Acesso em: 17 maio 2019.

NEVES, S. I. O. Terminal Intermodal de passageiros em Sorocaba-SP. 2014. $94 \mathrm{f}$. Monografia (Graduação em Arquitetura e Urbanismo) - Universidade Tecnológica Federal do Paraná. Curitiba, 2014.

OLIVEIRA, P. D.; GAST, K. R. Terminais Rodoviários, espaços em esquecimento: O caso de Mondaí - SC. V Simpósio Nacional de Gerenciamento de Cidades. 3a Semana de Arquitetura e Urbanismo da UNIVAG. Várzea Grande, 2017.

PASSINI, F. B.; LUNKES, R. B.; FAZOLO, N. Equipamento publico: terminal rodoviário para a cidade de Xanxerê em Santa Catarina. Anuário Pesquisa e Extensão UNOESC Xanxerê, 2018. 


\section{PORDEUS, E. Terminal Rodoviário de Sousa é um Exemplo da Incompetência do Poder} Público Municipal. 2018. Disponível em: <http://www.conexaopb.com.br/single.php?code=3038>. Acesso em: 13 nov. 2018.

QUEIROZ, F. L. O.; MAGALHÃES, S. L. M. Avaliação Física e Operacional dos Terminais Rodoviários de Passageiros com base no MITERP e NBR 9050 - Estudo de Caso Troncal Sul de Mato Grosso. E\&S - Engineering and Science. v. 1, ed. 5, 2016. Disponível em: $<$ http://www.periodicoscientificos.ufmt.br/ojs/index.php/eng/article/view/3375/4737>. Acesso em 15 nov 2018.

ROCHA, Germana Costa. O caráter tectônico do Moderno Brasileiro: Bernardes e Campello na Paraíba (1970-1980). 2012. 246. Tese (Doutorado em Arquitetura e Urbanismo) Universidade Federal do Rio Grande do Norte. Natal, 2012.

SOARES, P. U. Procedimento para a localização de terminais rodoviários interurbanos, interestaduais e internacionais de passageiros. 2006. $354 \mathrm{f}$. Dissertação (Mestrado em Engenharia de Transportes) - Universidade Federal do Rio de Janeiro. Rio de Janeiro, 2006. 